\title{
Neurofibromatose tipo 1 na infância: revisão dos aspectos clínicos
}

\author{
Neurofibromatosis type 1 in childhood: review of clinical aspects
}

Luiz Guilherme Darrigo Junior', Aguinaldo Bonalumi Filho², Denise Silvia M. D'Alessandro³, Mauro Geller ${ }^{4}$

\section{RESUMO}

Objetivo: Realizar uma revisão da literatura sobre neurofibromatose tipo 1 (NF1) em crianças e adolescentes, enfatizando as manifestações clínicas.

Fontes de dados: Artigos publicados, indexados na base de dados Medline e publicados entre 1998 a 2007, buscados pelos seguintes termos: "neurofibromatosis type 1", "neurofibroma", "von Recklinghausen" e "optic patbway gliomas".

Síntese dos dados: A NF1 é uma doença genética autossômica dominante, crônica e progressiva, com incidência de 1/2.000 a 1/7.800 nascidos vivos. Tem sido observada em diferentes partes do mundo, em todas as raças e nos dois sexos. Metade dos casos representa mutações novas. A taxa de mutação para o gene NF1 é de 1/10.000, a qual se deve ao fato do gene ser grande e possuir estrutura interna atípica, que predispõe a deleções e mutações. O diagnóstico presuntivo da NF1 é feito por critérios clínicos. As três principais manifestações - neurofibromas, manchas café-com-leite e nódulos de Lisch - ocorrem em mais de $90 \%$ dos pacientes até a puberdade.

Conclusões: Os cuidados com os pacientes com NF1 devem antecipar as principais complicações e oferecer um tratamento precoce. No aconselhamento genético, é importante informar pais e familiares a respeito do panorama geral da doença e suas possíveis complicações, enfatizando que a maioria dos pacientes apresenta vida saudável e produtiva.

Palavras-chave: neurofibromatoses; neurofibroma; criança.

\section{ABSTRACT}

Objective: To review clinical and diagnostic features of neurofibromatosis type 1 (NF1) in children and adolescents.

Data sources: Articles published from 1998 to 2007 and retrieved by the words "neurofibromatosis type 1"; "neurofibroma”, "von Recklinghausen" and "optic pathway gliomas" in Medline database.

Data synthesis: NF1 is a chronic and progressive autosomal dominant disorder with an incidence of $1 / 2,000$ to $1 / 7,800$ live births. There is no racial, geographic or gender preference. Half of the cases represent new mutations, and the mutation rate for NF1 gene is 1/10.000. The high mutation rate of NF1 may reflect the fact that the gene is large and/or that it has an unusual internal structure, predisposing it to deletions and other mutations. The presuntive diagnosis of NF1 is made on clinical basis. The three main features - neurofibromas, café-au-lait spots and Lisch nodules - are present in more than $90 \%$ of all affected patients until puberty.

Conclusions: The mainstay of care for patients with NF1 is anticipatory guidance and early detection and treatment of disease complications. Counseling of patients and their families should provide a realistic overview of possible clinical complications, while emphasizing that most individuals with NF1 have healthy and productive lives

Key-words: neurofibromatoses; neurofibroma; child.
${ }^{1}$ Residente em Pediatria do HSPM de São Paulo, São Paulo, SP, Brasil
2Professor da pós-graduação de Dermatologia do Hospital Naval Marcílio
Dias, Rio de Janeiro, RJ, Brasil
${ }^{3}$ Médica preceptora da residência de Pediatria do Hospital do Servidor
Público Municipal (HSPM) de São Paulo, São Paulo, SP, Brasil
4Professor titular de Imunologia e Microbiologia da Faculdade de Medicina
da Fundação Educacional Serra dos Órgãos e membro do Conselho Diretor
da International Neurofibromatosis Association, Rio de Janeiro, RJ, Brasil

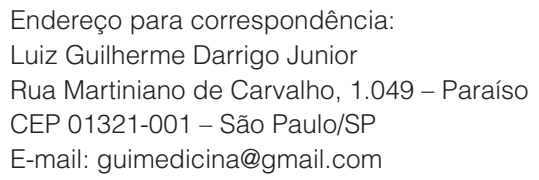

Endereço para correspondência:

Luiz Guilherme Darrigo Junior

Rua Martiniano de Carvalho, 1.049 - Paraíso

CEP 01321-001 - São Paulo/SP

E-mail: guimedicina@gmail.com

Recebido em: 26/10/2007

Aprovado em: 22/1/2008 


\section{Aspectos históricos}

A neurofibromatose tipo 1 (NF1) foi descrita em 1882 pelo médico Friederich Daniel von Recklinghausen, apesar de existirem 168 citações em publicações anteriores. Esse médico observou a existência de tumores no nervo e utilizou o termo neurofibroma para o tumor e neurofibromatose para a condição de múltiplos neurofibromas ${ }^{(1)}$. No século XIX, Joseph Carey Merrick descreveu um indivíduo cuja condição clínica sugere a síndrome de Proteus (conhecido como "Homem Elefante"), associada à NF1. A denominação popular trouxe estigmas sociais, uma vez que tal indivíduo era apresentado em circos, despertando a atenção de muitos médicos ${ }^{(2)}$. Em 1900, Thomson salientou o caráter hereditário da NF1. Preiser e Devenport, em 1918, esclareceram que a doença não era ligada ao sexo e que seguia os mecanismos de herança propostos por Mendel, como um caráter autossômico dominante. Em 1940, Davis descreveu o glioma óptico associado à NF1 ${ }^{(2)}$. No final da década de 1990, Barker et al e Seizinger et al mapearam o gene da NF1 no braço longo do cromossomo $17^{(2)}$.

\section{Prevalência}

Estima-se que a prevalência da NF-1 seja de 1:2.000 a 1:7.800 nascidos vivos, caracterizando-a como uma das doenças genética de herança autossômica dominante (AD) mais freqüentes ${ }^{(3-5)}$. Vários estudos demonstraram que $50 \%$ das crianças acometidas herdam a condição de seus familiares e a outra metade decorre de mutações novas, ou seja, os pais são sadios ${ }^{(3)}$. Os estudos epidemiológicos evidenciaram alta prevalência da NF-1 em indivíduos jovens ${ }^{(6)}$. Até o momento, não existem evidências de predomínio da NF-1 em determinadas populações ou gênero ${ }^{(5)}$.

\section{Aspectos genéticos}

A NF1 ocorre comumente em uma ou duas gerações. Em algumas famílias, ocorre em quatro a seis gerações ${ }^{(7)}$. O termo "expressividade" refere-se à variabilidade de sinais físicos ou clínicos associados a um dado gene. A NF-1 é uma das doenças genéticas que melhor exemplifica tal fenômeno, uma vez que há ampla variabilidade clínica, mesmo intrafamiliar. Além disso, um paciente gravemente acometido pode gerar descendentes com quadro clínico mais leve e vice-versa ${ }^{(7)}$.

O gene da NF-1 está mapeado em 17q12-22, sendo constituído por 51 éxons, com $350 \mathrm{~Kb}$ de comprimento, o que justifica a elevada taxa de mutação espontânea. A penetrância do gene NF-1 é completa (estimada em 100\%), ou seja, o indivíduo que possui o gene mutante expressa as manifestações clínicas ${ }^{(7)}$.

As análises moleculares do gene NF-1 disponíveis utilizam a técnica da Hibridização In Situ por Fluorescência (FISH) e seqüenciamento completo do gene NF-1 para pesquisar mutações em ponto. Aproximadamente 4 a $5 \%$ dos indivíduos acometidos pela NF-1 apresentam deleções de todo o gene da NF $1^{(8)}$. O fenótipo desses pacientes tende a ser mais grave, com início precoce dos neurofibromas e presença de deficiência mental, características dismórficas variáveis e outras anomalias congênitas ${ }^{(8)}$.

\section{Diagnóstico}

A NF-1 aparece mais freqüentemente na infância e o diagnóstico baseia-se na presença dos critérios clínicos desenvolvido pelo National Institutes of Health (NIH) Consensus Development Conference ${ }^{(9,10)}$. O diagnóstico precoce da NF-1 é benéfico para as crianças acometidas e para os seus familiares, uma vez que permite oferecer aos parentes aconselhamento genético apropriado, facilitando a intervenção precoce em complicações que serão descritas a seguir ${ }^{(3)}$. Os estudos demonstram que $70 \%$ dos pacientes com NF-1 podem ser diagnosticados antes de um ano de idade.

Os casos decorrentes de transmissão vertical, ou seja, um dos genitores também é acometido pela NF-1, podem ser identificados durante o primeiro ano de vida, uma vez que o diagnóstico requer apenas uma característica adicional, além da história familiar positiva ${ }^{(3)}$. Apesar disso, há dificuldades no diagnóstico da doença, principalmente em crianças menores, uma vez que aproximadamente $50 \%$ dos casos são esporádicos e alguns sinais da NF-1, como as efélides, os neurofibromas e os nódulos de Lisch, surgem no decorrer da vida $^{(11)}$. O diagnóstico, nessas crianças, poderá ser realizado por volta dos quatro anos de idade, seguindo os critérios do $\mathrm{NIH}^{(2)}$. No entanto, os critérios do NIH podem ser insuficientes para o diagnóstico da NF-1 em casos esporádicos, ou seja, em crianças que são casos únicos em suas famílias e manifestam somente manchas café-com-leite (MCCL), sem outras alterações. Nesses casos, recomenda-se o acompanhamento anual do paciente e pode-se indicar o teste molecular para a confirmação da NF-1.

O teste genético (ou molecular) para a NF-1 identifica aproximadamente $95 \%$ das mutações em indivíduos que preenchem os critérios diagnósticos clínicos ${ }^{(12)}$. Esse estudo 
molecular pode beneficiar aqueles indivíduos com somente um critério ou quando o diagnóstico é incerto. O resultado positivo do teste molecular não pode predizer a presença, a idade de início ou a gravidade dos sintomas da NF-1. É importante salientar que o resultado negativo, na ausência de uma mutação familial conhecida, não exclui o diagnóstico ${ }^{(12)}$.

O critério diagnóstico para NF-1 originalmente desenvolvido pelo NIH Consensus Development Conference ${ }^{(13)}$ admite duas ou mais das seguintes características clínicas:

1. Seis ou mais MCCL com diâmetro acima de $5 \mathrm{~mm}$ em indivíduos pré-púberes ou acima de $15 \mathrm{~mm}$, em pós-púberes.

2. Dois ou mais neurofibromas de qualquer tipo ou um neurofibroma plexiforme, baseado em parâmetros clínicos e histológicos.

3. Efélides (sardas) em região axilar ou inguinal.

4. Glioma óptico.

5. Dois ou mais nódulos de Lisch (harmatomas pigmentados da íris).

6. Uma lesão óssea distinta como pseudo-artrose de um osso longo ou displasia da asa do esfenóide.

7. Um parente em primeiro grau com NF-1 que preencha os critérios precedentes.

Embora a penetrância do gene da NF-1 seja completa, as manifestações clínicas desse distúrbio são extremamente variáveis ${ }^{(2)}$.

As MCCL ocorrem em 99\% dos pacientes com NF-1 e são caracteristicamente ovais, com bordas irregulares, áreas planas e sua coloração varia do amarelo ao marrom. Possuem uma predileção por áreas não expostas ao sol, são assintomáticas e raramente sofrem alterações malignas ${ }^{(2)}$. Apesar de se tratarem da mais freqüente característica clínica de NF-1 em crianças, as MCCL não são patognomônicas, uma vez que aparecem em outras entidades como esclerose tuberosa, síndrome de McCune-Albright, ataxia telangiectásica, síndrome de Bloom, anemia de Fanconi, síndrome de Silver-Russell, síndrome de Leopard, síndrome de Watson, cilindromatose, síndrome de Noonan e MCCL familiais ${ }^{(2)}$. No entanto, as MCCL estão presentes em menos de $10 \%$ da população geral. Assim, recomenda-se que crianças com seis ou mais MCCL acima de $5 \mathrm{~mm}$ de diâmetro ao nascimento sejam acompanhadas, uma vez que a maioria destas irá desenvolver outras manifestações da NF-1, as quais poderão surgir somente no final da infância ou mesmo na adolescência ${ }^{(2,14)}$.

As efélides são máculas lentiginosas menores que $5 \mathrm{~mm}$ e constituem, geralmente, a segunda manifestação clínica mais freqüente em crianças $^{(3)}$. Na maioria dos pacientes com NF-1, as efélides apresentam-se na região axilar e in- guinal. Outras localizações comuns incluem nuca, pescoço e região inframamária nas mulheres. Desse modo, a presença de múltiplas efélides menores que $5 \mathrm{~mm}$ em região axilar, inguinal e pescoço é altamente sugestiva de NF-1 ${ }^{(15)}$. Existe variação populacional no padrão das efélides, sendo comum nos negros e pouco freqüentes nos asiáticos ${ }^{(15)}$. As efélides acometem até $90 \%$ dos pacientes com idade até sete anos e são consideradas como critério diagnóstico importante na infância e na pré-adolescência ${ }^{(3,9)}$.

Os neurofibromas são tumores constituídos por células de Schawann, associados ou não a axônios, fibroblastos e células perineurais ${ }^{(16-18)}$. Estes tumores são benignos e não sofrem transformação maligna, sendo observados em $48 \%$ dos pacientes aos dez anos de idade e em $84 \%$ aos $20 \operatorname{anos}^{(3,17)}$. O tumor normalmente expressa a proteína S-100, um marcador antigênico que indica a origem neural das células ${ }^{(16)}$. Há vários tipos de neurofibromas, sendo os mais comuns aqueles localizados na pele. Estes crescem e formam lesões pediculares ou nodulares. Outros neurofibromas incluem os de localização intraneural, os difusos que envolvem pele e tecido submucoso e os tumores moles. Nestes últimos, observa-se infiltração difusa no tecido mole do corpo, destacando-se a formação de grandes massas que podem desfigurar o organismo, como os neurofibromas plexiformes (NFP) ${ }^{(16)}$.

Os NFP consistem de proliferação de células da bainha do nervo e estendem-se ao longo deste ${ }^{(16)}$. Em um estudo populacional, Huson et al $l^{(6)}$ observaram que $27 \%$ dos pacientes com NF-1 apresentavam NFP evidentes no exame físico. Outro estudo revelou a presença de NFP na região torácica em 9/240 crianças por meio de exame de imagem, sendo somente três delas sintomáticas ${ }^{(19)}$. Em uma série de casos, observou-se que 17\% (12/72) dos NFP foram diagnosticados no primeiro ano de vida, sendo que seis destes já estavam presentes ao nascimento. Além disso, $44 \%$ (32/72) foram diagnosticados antes dos cinco anos de idade ${ }^{(17)}$. Os NFP ocorrem principalmente no tronco (44\%), membros $(38 \%)$ e na cabeça e pescoço $(18 \%)^{(6)}$. $\mathrm{O}$ risco de desenvolver um tumor maligno na bainha do nervo é de 2 a $5 \%$, o que torna a NF-1 causa importante de morbimortalidade ${ }^{(17)}$. O crescimento dos NFP pode ocorrer em qualquer idade; contudo, parece haver preferência por dois períodos distintos. O primeiro ocorre na infância, quando o NFP cresce rapidamente por vários anos, e cessa de repente ou continua a crescer de modo constante. No segundo período, observa-se crescimento quando existem alterações hormonais, principalmente durante a puberdade ou, nas mulheres, durante a gravidez ${ }^{(20)}$. 
Os NFP podem crescer e invadir tecidos vizinhos durante a infância, devendo-se considerar a intervenção precoce para impedir o desenvolvimento de complicações estéticas e funcionais. No entanto, NFP pequenos raramente podem ser removidos por inteiro e seu crescimento pode se reativar após a cirurgia ${ }^{(21)}$. Desse modo, é difícil justificar a ressecção de NFP pequenos. Neste sentido, a decisão quanto à remoção cirúrgica do NFP ainda constitui um grande desafio ${ }^{(21)}$. Em estudos recentes, Friedrich et $a^{(22)}$ sugerem que a vantagem das intervenções cirúrgicas precoces nos NFP pequenos nas crianças seria impedir a progressão dos mesmos.

Os gliomas ópticos estão entre os tumores mais freqüentemente observados na NF-1, associados aos neurofibromas. O gene NF-1 é um gene supressor tumoral para determinadas células. Desse modo, mutações nesse gene causam risco elevado para o desenvolvimento de tumores benignos e malignos nas crianças - particularmente, tumores intracranianos como os gliomas ópticos ${ }^{(15)}$. Esses tumores são diagnosticados em $1 \%$ dos pacientes sintomáticos com um ano de idade e em $4 \%$ das crianças com NF-1 aos três anos de idade ${ }^{(3)}$. A prevalência de gliomas ópticos em pacientes com NF-1 é de 11 a 19\%, enquanto, na população geral, é em torno de 1:100.000 ${ }^{(23)}$. Os estudos demonstram que o principal período de risco para o desenvolvimento de glioma óptico sintomático em crianças com NF-1 ocorre durante os seis primeiros anos de vida, principalmente entre dois e quatro anos. $\mathrm{O}$ desenvolvimento de tumores sintomáticos após os seis anos de idade é extremamente raro $^{(24,25)}$. A maioria das crianças sintomáticas apresenta anormalidades visuais no momento do diagnóstico: defeito pupilar aferente, atrofia do nervo óptico, papiledema, estrabismo ou defeito na visualização de cores. Quanto à sua localização, o glioma óptico geralmente acomete a via anterior (nervo óptico intraorbital, nervo óptico intracranial e quiasma óptico) e, raramente, estende-se para o interior do trato óptico. As crianças com glioma óptico geralmente apresentam pouca ou nenhuma visão no olho acometido. A maioria dos estudos descreve a ocorrência de proptose em cerca de $30 \%$ das crianças com tumor sintomático ${ }^{(24)}$. Há evidências de que os tumores localizados próximos ao hipotálamo interferem no sistema nervoso central (SNC), inibindo o eixo hipotálamo-pituitário-gonadal, o que resultaria em início precoce da puberdade.

No passado, muitas crianças com NF-1 e glioma óptico eram submetidas a tratamento agressivo; todavia, atualmente, com o conhecimento de que a maioria destes tumores não apresenta progressão, os pacientes podem ser acompanhados sem intervenção específica ${ }^{(26,27)}$. Apesar do rastreamento tumoral por meio de neuroimagem não ser recomendado, a NF-1 Optic Pathway Gliomas Task Force of the National Neurofibromatosis Foundation recomenda exames oftalmológicos detalhados em crianças acometidas pela NF-1. Além disso, indica-se a ressonância nuclear magnética de cabeça e órbita com contraste para todas as crianças que apresentam anormalidades oftalmológicas inexplicadas ${ }^{(26)}$.

Os nódulos de Lisch são lesões hamartomatosas, bilaterais e bem definidas, que consistem em elevações gelatinosas na superfície da íris, de forma arredondada, variando de coloração transparente a amarelo ou marrom. Tais nódulos diferem dos nevi íris devido à morfologia, pois esses são constituídos de melanócitos e derivam da crista neural. A presença de múltiplos nódulos de Lisch parece ser exclusiva da síndrome de von Recklinghausen ${ }^{(28)}$. Os nódulos de Lisch afetam mais de $70 \%$ dos pacientes com NF-1 aos dez anos de idade ${ }^{(3)}$.

As alterações ósseas, como a pseudo-artrose, ocorrem em cerca de $5 \%$ das crianças com NF-1 e, em geral, são benignas, embora alguns pacientes sejam gravemente acometidos com arqueamento de ossos longos até fraturas ${ }^{(21)}$. Como a pseudo-artrose é observada em uma minoria dos pacientes ao nascimento, alguns autores entendem que o termo pseudo-artrose congênita não é apropriado e que deveria ser substituído por pseudo-artrose infantil. Essa anomalia é rara, ocorrendo em 1:140.000 nascimentos, e se torna evidente no primeiro ano de vida. Aproximadamente $50 \%$ dos casos de pseudo-artroses são devido à NF-1 ${ }^{(21)}$. Em geral, a pseudo-artrose está limitada a uma localização, sendo a tíbia o osso mais acometido, seguido pelo rádio e fêmur. O exame físico nos quatro membros é imprescindível para detectar a instabilidade óssea nos locais da pseudo$\operatorname{artrose}^{(21)}$. O tratamento varia desde o acompanhamento por imagem, nos casos mais brandos, até a amputação nos mais graves. Ainda o adelgaçamento da cortical óssea e a curvatura dos ossos longos são lesões ósseas displásicas que podem acometer os pacientes com NF-1. As asas do osso esfenóide também podem ser displásicas. Além disso, eventualmente ocorrem alterações na parede da órbita e sela túrcica, resultando em exoftalmia ${ }^{(21)}$.

Dentre as manifestações inespecíficas da NF-1, destacamse os deficits cognitivos, de linguagem e motores, com desordem de aprendizado, a escoliose e o aparecimento de doenças cancerosas, entre outras.

A NF-1 é a doença monogênica que mais comumente causa dificuldade de aprendizagem ${ }^{(29)}$. O termo desordem/ 
deficit de aprendizado encontra-se reservado para um modelo de função cognitiva no qual os sistemas de pontuação obtidos em testes acadêmicos (leitura, pronúncia, ortografia e matemática) são significativamente inferiores às pontuações do teste de inteligência ${ }^{(30)}$. A incidência da desordem de aprendizado em crianças com NF-1 é quatro vezes maior do que na população em geral $^{(29)}$, estimando-se uma prevalência do distúrbio na população com NF-1 de 25 a $60 \% \%^{(31-33)}$. Alguns estudos indicam que tal prevalência seria superior a $80 \%$, sendo considerada a maior causa de morbidade em pacientes com NF-1 $1^{(34)}$.

Estima-se que 4 a $8 \%$ dos indivíduos com NF-1 apresentem deficiência mental, com disfunção no desenvolvimento da linguagem e da coordenação visuo-espacial e visuomotora ${ }^{(35)}$. Johnson et al ${ }^{(36)}$ mostram que as crianças portadoras de NF-1 apresentam risco elevado para transtornos sociais e emocionais, quando comparadas à população geral e com seus irmãos não acometidos pela NF-1. Os autores propõem, como intervenção, avaliação e tratamento das alterações cognitivas, motoras e na fala (pois, tais aspectos, se não tratados, poderão levar a complicações emocionais ou de adaptação social posterior), acompanhados de avaliação emocional regular.

As causas das dificuldades de aprendizado associadas à NF-1 são desconhecidas ${ }^{(27)}$. Os estudos mais recentes de Hyman $e t$ $a l^{(37)}$ evidenciaram associação entre lesões no tálamo e o deficit cognitivo em pacientes com NF-1. No entanto, a NF-1 não deve ser considerada como fator limitante para o aprendizado infantil. O acompanhamento em escolas especiais estaria indicado apenas para casos graves ${ }^{(32)}$.

Apesar do diagnóstico presuntivo de NF-1 ser estabelecido clinicamente, a ressonância nuclear magnética é considerada como exame de escolha para o acompanhamento de crianças portadoras da condição ${ }^{(38)}$. Com a prática da ressonância, evidenciaram-se, em algumas crianças, áreas cerebrais anormais bem definidas, com sinal intenso nas sequiências em T2. Essas áreas foram denominadas de neurofibromatosis type 1 bright objects $(\mathrm{NBO})^{(38)}$ e correspondem a alterações vasculares ou espongióticas na substância cerebral $^{(39)}$. A seguir, demonstrou-se que tais alterações são freqüentes em crianças ( 43 a $77 \%$ dos pacientes com NF-1) e raras nos adultos ${ }^{(38)}$. O cerebelo parece ser o principal local de ocorrência de $\mathrm{NBO}^{(38)}$. A maioria destas imagens involui no decorrer dos anos, tendendo a desaparecer em número e tamanho. Apesar do Comitê de Genética da Sociedade Americana de Pediatria não recomendar o ressonância magnética no seguimento de crianças com NF-1 assinto- mática (exceto aquelas com glioma óptico), alguns autores sugerem a realização do exame em crianças com NF-1 que apresentam NBO múltiplos ou atípicos entre sete e $12 \operatorname{anos}^{(38)}$. Como os NBO são freqüentes em crianças, DeBella $e t ~ a l^{(39)}$ sugerem a sua presença como critério diagnóstico em crianças com NF1.

A escoliose é a principal anormalidade esquelética nos pacientes com NF-1 e ocorre em 10 a $60 \%$, sendo a maioria dos casos antes dos 15 anos $^{(40,41)}$. A curva na coluna vertebral geralmente ocorre na região dorsal, com tendência a produzir uma curva curta de ângulo agudo, comprometendo quatro a seis vértebras. A evolução da escoliose na NF-1 é progressiva ${ }^{(41)}$.

Pacientes com NF-1 apresentam predisposição ao desenvolvimento de certos tipos de cânceres, incluindo tumor maligno da bainha do nervo, astrocitoma, feocromocitoma, rabdomiossarcoma e leucemia mielomonocítica juvenil ${ }^{(42-}$ 44). Apesar da minoria dos pacientes apresentar malignidade como complicação, esta constitui importante fator de morbidade ${ }^{(43)}$, sendo a principal causa de mortalidade nos pacientes com NF- ${ }^{(45)}$. Shearer et al ${ }^{(46)}$ identificaram 32 pacientes com NF-1 em estudo de revisão de 6.678 crianças que receberam tratamento para câncer em centro de referência. Os tumores mielóides podem ocorrer em crianças, uma vez que o gene NF-1 atua como supressor de tumor ${ }^{(18)}$. Diante de neoplasias malignas em crianças acometidas pela NF1, o protocolo de tratamento deverá ser igual ao das não portadoras da doençą ${ }^{(47)}$.

Além das manifestações acima descritas, as crianças com NF-1 podem apresentar epilepsia, hipertensão, estenose vascular, obstrução intestinal, constipação, hemorragia, cistos ósseos, baixa estatura e macrocefalia ${ }^{(43)}$.

Alguns autores sugerem que modificações nos critérios diagnósticos do NIH poderiam levar a diagnósticos mais precisos, particularmente nas crianças ${ }^{(3,21)}$. Tais modificações deveriam incluir a baixa estatura, a macrocefalia e a presença de NBO em exames de ressonância magnética.

\section{Tratamento e acompanhamento}

Ainda não há um tratamento médico eficaz para prevenir ou reverter as lesões características da NF-1, exceto a detecção precoce de complicações tratáveis e o aconselhamento genético ${ }^{(48)}$. No entanto, vários estudos clínicos com diferentes drogas têm sido conduzidos, sugerindo que o tratamento farmacológico da NF-1 torne-se realidade em breve ${ }^{(49)}$. Enquanto isso, o médico deve informar aos pais que o acompanhamento de uma criança com NF-1 é um processo multidisciplinar, de longa 
duração e que existem roteiros preventivos para antecipar as possíveis complicações, de acordo com a faixa etária da criança acometida pelo distúrbio ${ }^{(50)}$. Assim, recomenda-se que crianças portadoras de NF-1 e que não apresentem complicações devam ser acompanhadas anualmente, de preferência por equipes miltiprofissionais ${ }^{(44,51,52)}$. Tomando por base a Academia Americana de Pediatria ${ }^{(47)}$, orienta-se a seguinte conduta:

- Em crianças, fazer exame clínico e avaliação periódica quanto ao surgimento de novos neurofibromas e progressão dos já existentes. O exame clínico da pele deve buscar sinais de NFP, que podem causar alterações orgânicas, funcionais e

\section{Referências bibliográficas}

1. Viskochil D. Neurofibromatosis 1. Am J Med Genet 1999;89:V-VIII.

2. Geller M, Bonalumi AF. Neurofibromatose. In: Carakushansky G. Doenças genéticas em pediatria. Rio de Janeiro: Guanabara Koogan; 2001. p.377-90.

3. DeBella K, Szudek J, Friedman JM. Use of the national institutes of health criteria for diagnosis of neurofibromatosis 1 in children. Pediatrics 2000;105:608-14.

4. Lammert M, Friedman JM, Kluwe L, Mautner VF. Prevalence of neurofibromatosis 1 in German children at elementary school enrollment. Arch Dermatol 2005;141:71-4.

5. Friedman JM. Epidemiology of neurofibromatosis type 1. Am J Med Genet 1999;89:1-6.

6. Huson SM, Harper PS, Compston DA. Von Recklinghausen neurofibromatosis. A clinical and population study in south-east Wales. Brain 1988;111:1355-81.

7. Geller M, Bonalumi Filho A, França FC, Nunes FP. Neurofibromatose (Síndrome de Von Recklinghausen): genética e NF2. J Bras Med 1999;76:36-9.

8. Kluwe L, Siebert R, Gesk S, Friedrich RE, Tinschert S, Kehrer-Sawatzki H et al. Screening 500 unselected neurofibromatosis 1 patients for deletions of the NF1 gene. Hum Mutat 2004;23:111-6.

9. Stoll C. Difficulties in the diagnosis of neurofibomatosis-1 in children. Am J Med Genet 2002;112:422-6.

10. Mulvihill JJ, Parry DM, Sherman JL, Pikus A, Kaiser-Kupfer MI, Eldridge R. $\mathrm{NIH}$ conference. Neurofibromatosis 1 (Recklinghausen disease) and neurofibromatosis 2 (bilateral acoustic neurofibromatosis). An update. Ann Intern Med 1990;113:39-52.

11. Korf BR. Diagnostic outcome in children with multiple cafe au lait spots. Pediatrics 1992;90:924-7.

12. Messiaen L, Riccardi V, Peltonen J, Maertens O, Callens T, Karvonen SL et al. Independent NF1 mutations in two large families with spinal neurofibromatosis. J Med Genet 2003;40:122-6.

13. Stumpf DA, Alksne JF, Annegers JF. Neurofibromatosis: conference statement. Arch Neurol 1988;45:575-8.

14. Wainer S. Child with axillary freckling and cafe au lait spots. CMAJ 2002;167:282-3.

15. Zvulunov A, Weitz R, Metzker A. Neurofibromatosis type 1 in childhood: evaluation of clinical and epidemiologic features as predictive factors for severity. Clin Pediatr (Phila) 1998;37:295-9.

16. Woodruff JM. Pathology of tumors of the peripheral nerve sheath in type 1 neurofibromatosis. Am J Med Genet 1999;89:23-30.

17. Waggoner DJ, Towbin J, Gottesman G, Gutmann DH. Clinic-based study of plexiform neurofibromas in neurofibromatosis 1. Am J Med Genet 2000;92:132-5.

18. Geller M, Bonalumi Filho A, França FC, Nunes FP. Neurofibromatose (Síndrome de Von Recklinghausen): 4: Gravidez e revisão de relatos clínicos; reprodução. J Bras Med 1999;76:76-82. estéticas ou se infiltrarem outras estruturas.

- Aferir a pressão arterial em todas as consultas. Deve-se relacionar os achados com a clínica, buscando doença renal (estenose da artéria renal), estenose da aorta, feocromocitoma e tumores de adrenal.

- Acompanhar com detalhe o neurodesenvolvimento.

- Acompanhar o desenvolvimento ósseo. Atenção para escoliose, angulação da coluna vertebral e anormalidades dos membros. A hipertrofia de uma perna, braço ou de outra parte do corpo pode ser resultado de um NFP.

- Disponibilizar informação ao paciente por meio de grupos de apoio, panfletos e livros que explorem o assunto.

19. Schorry EK, Crawford AH, Egelhoff JC, Lovell AM, Saal HM. Thoracic tumors in children with neurofibromatosis-1. Am J Med Genet 1997;74:533-7.

20. Dugoff L, Sujansky E. Neurofibromatosis type 1 and pregnancy. Am J Med Genet 1996;66:7-10.

21. Geller M, Bonalumi Filho A, editores. Neurofibromatose: clínica, genética e terapêutica. Rio de Janeiro: Guanabara Koogan; 2004.

22. Friedrich RE, Schmelzle R, Hartmann M, Fünsterer C, Mautner VF. Resection of small plexiform neurofibromas in neurofibromatosis type 1 children. World J Surg Oncol 2005;3:6.

23. Singhal S, Birch JM, Kerr B, Lashford L, Evans DG. Neurofibromatosis type 1 and sporadic optic gliomas. Arch Dis Child 2002;87:65-70.

24. Listernick R, Charrow J, Greenwald M, Mets M. Natural history of optic pathway tumors in children with neurofibromatosis type 1: a longitudinal study. J Pediatr 1994;125:63-6.

25. Listernick R, Charrow J, Greenwald M. Emergence of optic pathway gliomas in children with neurofibromatosis type 1 after normal neuroimaging results. J Pediatr 1992;121:584-7.

26. Listernick R, Charrow J, Gutmann DH. Intracranial gliomas in neurofibromatosis type 1. Am J Med Genet 1999;89:38-44.

27. Geller M, Bonalumi Filho A. Aspectos do desenvolvimento cognitivo e da comunicação, linguagem e aprendizado. In: Geller M, Bonalumi AF, editores. Neurofibromatose: clínica, genetica e terapêutica. Rio de Janeiro: Guanabara Koogan; 2004. p. 126-9.

28. Geller M, Bonalumi Filho A, França FC, Nunes FP. Neurofibromatose (Síndrome de Von Recklinghausen): histórico, diagnóstico, exames clínicos e laboratoriais. J Bras Med 1998;75:15-21.

29. Costa RM, Silva AJ. Déficits de aprendizagem associados à NF-1: de modelos à terapêutica. In: Geller M, Bonalumi AF, editores. Neurofibromatose: clínica, genética e terapêutica. Rio de Janeiro: Guanabara Koogan; 2004. p. 130-5.

30. Ozonoff S. Cognitive impairment in neurofibromatosis type 1. Am J Med Genet 1999;89:45-52.

31. Brewer VR, Moore BD 3rd, Hiscock M. Learning disability subtypes in children with neurofibromatosis. J Learn Disabil 1997;30:521-33.

32. Carey JC. Neurofibromatosis-Noonan syndrome. Am J Med Genet 1998;75:263-4.

33. Hofman KJ, Harris EL, Bryan RN, Denckla MB. Neurofibromatosis type 1: the cognitive phenotype. J Pediatr 1994;124:S1-8.

34. Acosta MT. The neurobiology of learning difficulties: neurofibromatosis type 1 as a model for researching and treating learning disorders. Rev Neurol 2007;44 (Suppl 2):S3-8.

35. Geller M, Bonalumi Filho A, França FC, Nunes FP. Neurofibromatose (Síndrome de Von Recklinghausen): desordens de aprendizado e comunicação, aspectos neurológicos e clínicos. J Bras Med 1998;75:61-4. 
36. Johnson NS, Saal HM, Lovell AM, Schorry EK. Social and emotional problems in children with neurofibromatosis type 1: evidence and proposed interventions. J Pediatr 1999;134:767-72.

37. Hyman SL, Gill DS, Shores EA, Steinberg A, North KN. T2 hyperintensities in children with neurofibromatosis type 1 and their relationship to cognitive functioning. J Neurol Neurosurg Psychiatry 2007;78:1088-91.

38. Griffiths PD, Blaser S, Mukonoweshuro W, Armstrong D, Milo-Mason G, Cheung $S$. Neurofibromatosis bright objects in children with neurofibromatosis type 1: a proliferative potential? Pediatrics 1999;104:e49.

39. DeBella K, Poskitt K, Szudek J, Friedman JM. Use of "unidentified bright objects" on MRI for diagnosis of neurofibromatosis 1 in children. Neurology 2000;54:1646-51.

40. Kim FM, Poussaint TY, Barnes PD. Neuroimaging of scoliosis in childhood. Neuroimaging Clin North Am 1999;9:195-221.

41. Mibielli MAN, Moreti D, Argollo BRT. Aspectos ortopédicos clínicos da neurofibromatose. In: Geller M, Bonalumi Filho A, editores. Neurofibromatose: clínica, genética e terapêutica. Rio de Janeiro: Guanabara Koogan; 2004. p. 101-8.

42. Weiss B, Bollag G, Shannon K. Hyperactive Ras as a therapeutic target in neurofibromatosis type 1. Am J Med Genet 1999;89:14-22.

43. Korf BR. Malignancy in neurofibromatosis type 1. Oncologist 2000;5:477-85.

44. Eichenfield LF, Levy ML, Paller AS, Riccardi VM. Guidelines of care for neurofibromatosis type 1. American Academy of Dermatology Guidelines/Outcomes
Committee. J Am Acad Dermatol 1997;37:625-30.

45. Rasmussen SA, Yang Q, Friedman JM. Mortality in neurofibromatosis 1: an analysis using U.S. death certificates. Am J Hum Genet 2001;68:1110-8.

46. Shearer P, Parham D, Kovnar E, Kun L, Rao B, Lobe T et al. Neurofibromatosis type I and malignancy: review of 32 pediatric cases treated at a single institution. Med Pediatr Oncol 1994;22:78-83.

47. No authors listed. Health supervision for children with neurofibromatosis. American Academy of Pediatrics Committee on Genetics. Pediatrics 1995;96:368-72.

48. Trovo AB, Goloni-Bertollo EM, Tajara EH. Neurofibromatose tipo 1: uma revisão. HB Científica 2002;9:98-110.

49. Theos A, Korf BR; American College of Physicians; American Physiological Society. Pathophysiology of neurofibromatosis type 1. Ann Intern Med 2006;144:842-9.

50. Carey JC. Health supervision and anticipatory guidance for children with genetic disorders (including specific recommendations for trisomy 21, trisomy 18, and neurofibromatosis I). Pediatr Clin North Am 1992;39:25-53.

51. Cnossen MH, de Goede-Bolder A, van den Broek KM, Waasdorp CM, Oranje AP, Stroink $\mathrm{H}$ et al. A prospective 10 year follow up study of patients with neurofibromatosis type 1. Arch Dis Child 1998;78:408-12.

52. Darrigo Jr LG, Geller M, Bonalumi Filho A, Azulay DR. Prevalence of plexiform neurofibroma in children and adolescents with type I neurofibromatosis. J Pediatr (Rio J) 2007;83:571-3. 